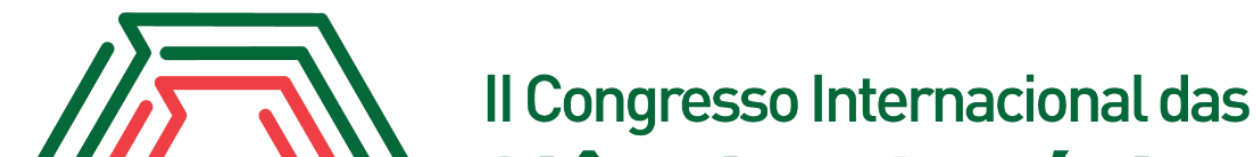 Ciências Agrárias COINTER - PDVAgro 2017
}

\section{AVALIAÇÃO DA FERTILIDADE DO SOLO PARA IMPLANTAÇÃO DE PASTO EM SÃO MIGUEL DO GUAMÁ-PARÁ}

Apresentação: Pôster

\begin{abstract}
Bruno Maia da Silva ${ }^{1}$; Sebastião Rodrigo do Remédio Souza Oliveira ${ }^{2}$; Vicente Mendonça Costa Neto $^{3}$; Vinicius Bruno Soares Borges ${ }^{4}$; Possidônio Guimaraes Rodrigues ${ }^{5}$
\end{abstract}

\section{Introdução}

Para a produção leiteira intensiva, o produtor precisa aplicar várias técnicas, de modo que torne o manejo adequado visando uma maior produtividade. Dentre as técnicas recomendadas objetivando o aumento da produção, está a boa nutrição, através do uso de alimentação balanceada, água suficiente, além da sombra. A pastagem contribui significativamente para a intensificação da pecuária leiteira, uma vez que ela consegue suprir a maior parte das exigências nutricionais do gado.

Entre as várias culturas indicadas para pastagem, o capim Mombaça (Megathyrsus maximus) é o mais utilizado devido sua qualidade e adaptação a diferentes condições de clima e solo, além deste ser conhecido mundialmente por sua alta produtividade.

Mas para o cultivo desta espécie há fatores que devem ser analisados, pois esse capim é exigente em fertilidade do solo. Segundo Euclides (2014) “O fósforo é o nutriente que mais limita a produção desse capim no Cerrado, por isso, a adubação fosfatada é imprescindível”.

Em estudo realizado pela Embrapa notou-se que em geral, as respostas mais positivas ao fósforo são dependentes, além da correção da acidez do solo, da adição de outros nutrientes como nitrogênio $(\mathrm{N})$, potássio $(\mathrm{K})$, enxofre $(\mathrm{S})$ e micronutrientes.

O presente trabalho teve por objetivo avaliar os atributos químicos do solo para implantação de um pasto de bovinocultura leiteira em São Miguel do Guamá.

\footnotetext{
${ }^{1}$ Eng. Florestal, Universidade Federal Rural da Amazônia, msbruno@outlook.com

${ }^{2}$ Eng. Florestal, Universidade Federal Rural da Amazônia, rodrigosouza6789@gmail.com

${ }^{3}$ Eng. Florestal, Universidade Federal Rural da Amazônia, vmnetocosta@ outlook.com

${ }^{4}$ Eng. Florestal, Universidade Federal Rural da Amazônia, vinicius_pgm_38@hotmail.com

${ }^{5}$ Professor do Instituto Federal do Pará, possirodrigues@gmail.com
} 


\section{Fundamentação Teórica}

A pastagem ainda é a forma mais utilizada devido sua praticidade e por ser menos onerosa quando se refere a alimentação de bovinos e caracteriza-se por ser a base da sustentação da atividade pecuarista no Brasil (FREIRE, 2012)

A necessidade da boa fertilização de uma pastagem de alto valor nutritivo e elevados índices de produtividade por hectare, é de extrema importância para o sucesso produtivo, no entanto, nem sempre isso é possível, devido a pequena quantidade de informações relacionados a necessidade nutricional de plantas forrageiras em diferentes condições de solo e fertilidade, para isso faz-se necessário a elaboração de estudos a respeito do assunto (MACEDO, 2013).

Outra questão que se deve atentar na hora da implantação de uma cultura é o local onde ela será cultivada, pois deve se conhecer a porosidade do solo pois este interfere na aeração, condução e retenção de água, resistência à penetração e à ramificação de raízes. Com isso, consequentemente, interferem no aproveitamento da água e dos nutrientes disponíveis para as plantas (RIBEIRO et al., 2007).

\section{Metodologia}

O trabalho foi realizado na Fazenda Barú (que contem área de 25 ha). A fazenda localiza-se no ramal do Tatuaia, em São Miguel do Guamá-Pa, mesorregião nordeste paraense, clima Afi com $2.000 \mathrm{~mm}$ anual de precipitação e $26^{\circ} \mathrm{C}$ de temperatura média anual.

O solo em estudo (Argissolo Vermelho concrecionário) apresentou textura arenosa (89\% de areia), declividade fraca, classe 2. A área teve histórico de exploração da floresta primária, seguido por cultivo de pastagem do gado de leite extensivo.

Para coleta das amostras, dividiu-se o terreno em glebas de 5 ha. Coletaram-se 50 amostras simples na camada 0-0,2 m que compuseram 5 amostras compostas. Determinaram-se os atributos químicos do solo relacionados à fertilidade. 


\section{Resultados e Discussão}

O potencial hidrogeniônico $(\mathrm{pH})$ foi medido em solução de $\mathrm{CaCl}_{2}$, onde obteve-se o valor de 4,3. Esse valor de $\mathrm{pH}$ indica elevada acidez ativa, que influencia na disponibilidade de cargas e consequentemente na disponibilidade de nutrientes. É o que se observa com os resultados dos cátions $\mathrm{Ca}$, Mg e K (0,861 cmolc dm-3), ou seja, baixa disponibilidade das bases trocáveis, o que diminui o grau de fertilidade do solo.

Segundo Camargo (2009) uma pequena disponibilidade de nutrientes disponíveis pode causar deficiências fisiológicas. O cálcio (Ca) nas gramíneas forrageiras é essencial para o crescimento do sistema radicular. "Sua deficiência provoca redução no sistema radicular, com morte da extremidade das raízes e como consequência, clorose nas folhas novas".

Outro elemento essencial que tem função vital para o funcionamento vegetal é o magnésio $(\mathrm{Mg})$, devido ele ser componente da clorofila, e auxilia também na absorção de fósforo. "Sua deficiência afeta o crescimento da planta sendo caracterizada por listras esbranquiçadas paralelas às nervuras nas folhas inferiores" (CAMARGO, 2009).

O potássio $(\mathrm{K})$ é essencial para o uso eficiente da água, pois este está diretamente ligado ao funcionamento dos estômatos. Sua deficiência é caracterizada pelo amarelecimento e bronzeamento nas margens das folhas inferiores. (sengik, 2003).

O elemento fósforo (P) apresentou uma baixa concentração $\left(3 \mathrm{mg} \mathrm{dm}^{-3}\right)$. Sua presença no solo é essencial para o crescimento das plantas forrageiras. Desempenha importante papel no desenvolvimento radicular e no perfilhamento das gramíneas. "Sua deficiência é caracterizada pela coloração púrpura (arroxeada) de colmos e folhas”. (SENGIK, 2003).

O solo apresentou a СТС ocupada por $\mathrm{H}+\mathrm{Al}(2,4$ cmolc dm-3) cerca de $73,6 \%$. Os resultados são típicos de solos altamente intemperados.

Observando as características físicas, pode-se dizer que este solo é arenoso, pois no mesmo foi constatada a porcentagem de areia (89\%) superior à porcentagem de argila e silte $(8 \%$ e $3 \%$ respectivamente), o que pode ser reforçado com estudo desenvolvido pela Embrapa onde ela descreve que "Solos arenosos são aqueles que apresentam menos de 15\% de argila. Estes solos possuem uma maior proporção de areia (70\%)" (EMBRAPA, 2003). 
Devido a maior predominância de areia, esse tipo de solo torna-se mais poroso e permeável, aumentando a taxa de drenagem, ou seja, a água atinge profundidade mais acentuada. E nesta movimentação da água para as camadas mais profundas, ela carrega junto os nutrientes essenciais às plantas.

Então para efeito de correção deste solo, recomenda-se aplicar calcário dolomítico (pois possui a uma maior proporção de magnésio) com PRNT de 75\% e elevar a saturação por bases (v\%) a $80 \%$.

Com relação a aplicação de adubo, recomenda-se aplicar de duas formas, uma para estabelecimento da cultura (inicial) e outra para manutenção (para se evitar diagnostico de deficiência) respectivamente, as quantidades a serem aplicada para as condições descritas anteriormente podem ser vistas na tabela abaixo (Tabela 1 Tabela 12)

Tabela 1- Recomendação de adubação de estabelecimento para o solo em estudo. Fonte: Rodrigo Oliveira

\begin{tabular}{ccc}
\hline \multicolumn{3}{c}{ Recomendação kg/ha } \\
\hline $\mathrm{N}$ & $\mathrm{P}_{2} \mathrm{O}_{5}$ & $\mathrm{~K}_{2} \mathrm{O}$ \\
\hline 30 & 60 & 60 \\
\hline \multicolumn{3}{c}{ Recomendação de N e K para estabelecimento } \\
\hline
\end{tabular}

Tabela 2- Recomendação de adubação de manutenção. Fonte: Rodrigo Oliveira

\begin{tabular}{ccc}
\hline \multicolumn{3}{c}{ Recomendação kg/ha } \\
\hline $\mathrm{N}$ & $\mathrm{P}_{2} \mathrm{O}_{5}$ & $\mathrm{~K}_{2} \mathrm{O}$ \\
\hline 170 & 60 & 200 \\
\hline \multicolumn{3}{c}{ Recomendação de manutenção de $\mathrm{N} \mathrm{e} \mathrm{K}$} \\
\hline
\end{tabular}

\section{Conclusões}

Devido às condições apresentadas pelo solo em estudo e visando seu melhor aproveitamento, faz-se necessário a recomendação de calagem com o objetivo de elevar seu nível de pH, além de disponibilizar cálcio e magnésio.

Recomenda-se também, adubação com NPK em níveis de exigência do cultivar, sendo ela aplicada de duas formas, uma na semeadura (estabelecimento) e outra será aplicada de forma parcelada, para evitar que possa aparecer deficiência (manutenção). 


\section{Referências}

CANTARUTTI, R.B et al. Recomendação para uso de corretivos e fertilizantes em minas gerais. Viçosa, MG: comissão de fertilidade do estado de minas gerais, 1999, p. 332-341.

Costa, N. L. Formação e manejo de pastagens de capim-Mombaça na Amazônia Ocidental. Disponível em: <https://www.ruralnews.com.br/visualiza.php?id=332>. Acesso em: 16 mar. 2017.

EMBRAPA ALGODÃO: sistema de produção. Disponível em: <http//:www.ft.unicamp.br/ sandro/st571/Solos\%20-\%20EMBRAPA\%20ALGODÃO.doc>. Acesso em: 18 MAR 2017.

EMBRAPA. Boletim de pesquisa e desenvolvimento: conceitos e fertilidade do solo e manejo adequado para regiões tropicais. Campinas, SP. 2010. 30p.

Euclides, V. P. B. Embrapa Gado de Corte: Manejo do capim-Mombaça para períodos de águas e seca. 2014. Disponível em: <https://www.embrapa.br/busca-de-noticias/-/noticia/2118000/artigomanejo-do-capim-mombaca-para-periodos-de-guas-e-seca>. Acesso em: 16 Mar. 2017.

MACÊDO, V. C. Adubação de implantação, manutenção e recuperação de capim Mombaça. 2013. 30 p. Trabalho de conclusão de curso (Bacharel em Zootecnia) - Universidade Federal de Goiás. Goiânia, 2013.

MARTHA JÚNIOR, G.B.; VILELA, L. Uso de fertilizantes em pastagens. In: MARTHA JÚNIOR, G.B.; VILELA, L.; SOUSA, D.M.G. Cerrado, uso eficiente de corretivos e fertilizantes em pastagens. 1.ed. Planaltina, 2007, p.43-68

RIBEIRO, K. D. et al. Propriedades físicas do solo influenciadas pela distribuição de poros, de seis classes de solos da região de Lavras-MG. Ciência Agrotécnica, Lavras, v. 31, n. 4, p. 1167-1175, julho/ago. 2007.

SENGIK, E.S. Os macronutrientes e os micronutrientes das plantas. Disponível em: <http//: www.ipef.br/servicos/teses/arquivos/silveira,rlva.pdf>. Acesso em: 16 mar. 2017. 